University of South Carolina

Scholar Commons

$11-19-2010$

\title{
Shelf Edge Tide Correlated Eddies Along the Southeastern United States
}

\author{
Dana K. Savidge \\ Jonathan Norman \\ Armstrong Atlantic State University \\ Colton Smith \\ Julie A. Amft \\ Trent Moore
}

See next page for additional authors

Follow this and additional works at: https://scholarcommons.sc.edu/geol_facpub

Part of the Earth Sciences Commons

\section{Publication Info}

Published in Geophysical Research Letters, Volume 37, Issue L22604, 2010, pages 1-6.

Savidge, D. K., Norman, J., Smith, C., Amft, J. A., Moore, T., Edwards, C., \& Voulgaris, G. (2010). Shelf edge tide correlated eddies along the southeastern United States. Geophysical Research Letters, 37 (L22604), $1-6$.

(c) Geophysical Research Letters 2010, American Geophysical Union

This Article is brought to you by the Earth, Ocean and Environment, School of the at Scholar Commons. It has been accepted for inclusion in Faculty Publications by an authorized administrator of Scholar Commons. For more information, please contact digres@mailbox.sc.edu. 


\section{Author(s)}

Dana K. Savidge, Jonathan Norman, Colton Smith, Julie A. Amft, Trent Moore, Catherine Edwards, and George Voulgaris 


\title{
Shelf edge tide correlated eddies along the southeastern United States
}

\author{
Dana K. Savidge, ${ }^{1}$ Jonathan Norman, ${ }^{2}$ Colton Smith, ${ }^{1}$ Julie A. Amft, ${ }^{1}$ Trent Moore, ${ }^{1}$ \\ Catherine Edwards, ${ }^{1}$ and George Voulgaris ${ }^{3}$ \\ Received 25 August 2010; revised 8 October 2010; accepted 18 October 2010; published 19 November 2010.
}

[1] High frequency radar observations in the Southeastern United States have revealed sequences of small short-lived cyclonic eddies along the shoreward edge of the Gulf Stream, that spin up as the local tide turns alongshelf antiparallel to the Stream. Eddies propagate equatorward along the shelf edge, sometimes progressing shoreward before dissipating one to three hours later. They are distinctly different from Gulf Stream meander eddies, which propagate poleward. In this article, radar and mooring data are used to establish three important aspects of these new eddies: they represent an instability process operating at a previously unidentified frequency, scale, and cross-Stream position; they contribute to shoreward momentum fluxes, defining a link between Gulf Stream and outer shelf subtidal variability and illustrating a mechanism to justify locally large horizontal eddy viscosity estimates; and they transport properties across the shelf edge, importing nutrients onto the shelf and transferring heat between the Gulf Stream and the coastal ocean. Citation: Savidge, D. K., J. Norman, C. Smith, J. A. Amft, T. Moore, C. Edwards, and G. Voulgaris (2010), Shelf edge tide correlated eddies along the southeastern United States, Geophys. Res. Lett., 37, L22604, doi:10.1029/2010GL045236.

\section{Introduction}

[2] In the southeastern United States, Gulf Stream (GS) variability correlates strongly with energetic alongshelf currents on the outer shelf [Atkinson et al., 1983]. Semidiurnal tides are also large, with an $M_{2}$ maximum on the Georgia shelf falling from $0.4 \mathrm{~m} / \mathrm{s}$ midshelf to $0.3 \mathrm{~m} / \mathrm{s}$ on the outer shelf [Pietrafesa et al., 1985; Blanton et al., 2004]. At the edge of this dynamic shelf region, a series of small short-lived cyclonic eddies have been observed in longrange high frequency (HF) radar data (Figure 1). They appear quite abruptly along the shoreward edge of the GS as the local $M_{2}$ tidal velocity vector sweeps clockwise from offshore to equatorward and alongshelf. More than one of these shelf-edge tide correlated (SETC) eddies can appear during any one tidal sweep. They then propagate southwestward along the shelf edge, sometimes moving shoreward as the tide turns shoreward, before dissipating one-three hours later.

\footnotetext{
${ }^{1}$ Skidaway Institute of Oceanography, Savannah, Georgia, USA.

${ }^{2}$ College of Science and Technology, Armstrong Atlantic State University, Savannah, Georgia, USA.

${ }^{3}$ Marine Science Program, Department of Geological Sciences, University of South Carolina, Columbia, South Carolina, USA.

Copyright 2010 by the American Geophysical Union. 0094-8276/10/2010GL045236
}

[3] The large volume of data available in the HF-radar archive (48 spatial maps of surface velocity data per day since April 2006) motivated the use of artificial neural networks to automate the detection of SETC eddies. These methods have seldom been used in oceanography, though examples do exist [Castellani, 2006]. Artificial neural networks facilitate pattern recognition with a series of yes-no decision-making steps, amassing statistics on the occurrence in space and time of those patterns. A detection frequency map (Figure 2, top) indicates high eddy incidence along the outer shelf, appearing in a timeseries of detections with a distinctly semi-diurnal character (Figure 2, bottom). Phasing is such that eddies appear as the clockwise rotating tide turns antiparallel to the strong northeastward flowing GS. Eddies do not survive transit very far shoreward, as incidence values fall off dramatically away from the shelf edge. The highest values in Figure 2 (top) occur where radar coverage is most complete in time. Inspection suggests eddy incidence is fairly evenly distributed alongshelf, though perhaps varying over time at fairly low frequency, presumably as Gulf Stream meandering alters shelf-edge velocity gradients. The February 2010 installation of an additional HF-radar south of the original two sites will increase alongshelf coverage sufficiently to address the question of local alongshelf variability in eddy generation more satisfactorily.

[4] SETC eddies are unlike other small eddies that have been reported on continental shelves. Counter-rotating eddies observed south of the Florida Keys adjacent to the Florida Current were of similar scale, but propagated in the GS downstream direction, hypothesized to have been a response to a sudden change in wind forcing [Shay et al., 1995]. Similar scale spiral eddies in satellite sun-glint imagery appear in groups with little apparent preferred orientation [Munk et al., 2000]. Middle Atlantic Bight shelfbreak front eddies are of similar spatial scale, but their temporal scale is longer, and the shelfbreak velocity and density spatial scales are significantly different than those at the shelfbreak in the southeast United States [Garvine et al., 1989; Fratantoni and Pickart, 2003].

[5] The equatorward propagating SETC eddies are also distinctly different from GS meander eddies, which propagate poleward within meanders along the shoreward flank of the GS. Upwelling by cyclonic eddies imbedded within those meanders import sufficient cold nitrate-rich waters into the euphotic zone to dominate new production on the continental shelf in the southeast, supporting $4.3 \times 10^{12} \mathrm{gC}$ per year [Lee et al., 1991]. SETC eddies are much more short-lived (a few hours) and somewhat smaller than GS meander eddies, and travel in the opposite alongshelf direction. Their swirl velocities can be as large as the local $M_{2}$ velocities with associated relative vorticity that ranges 


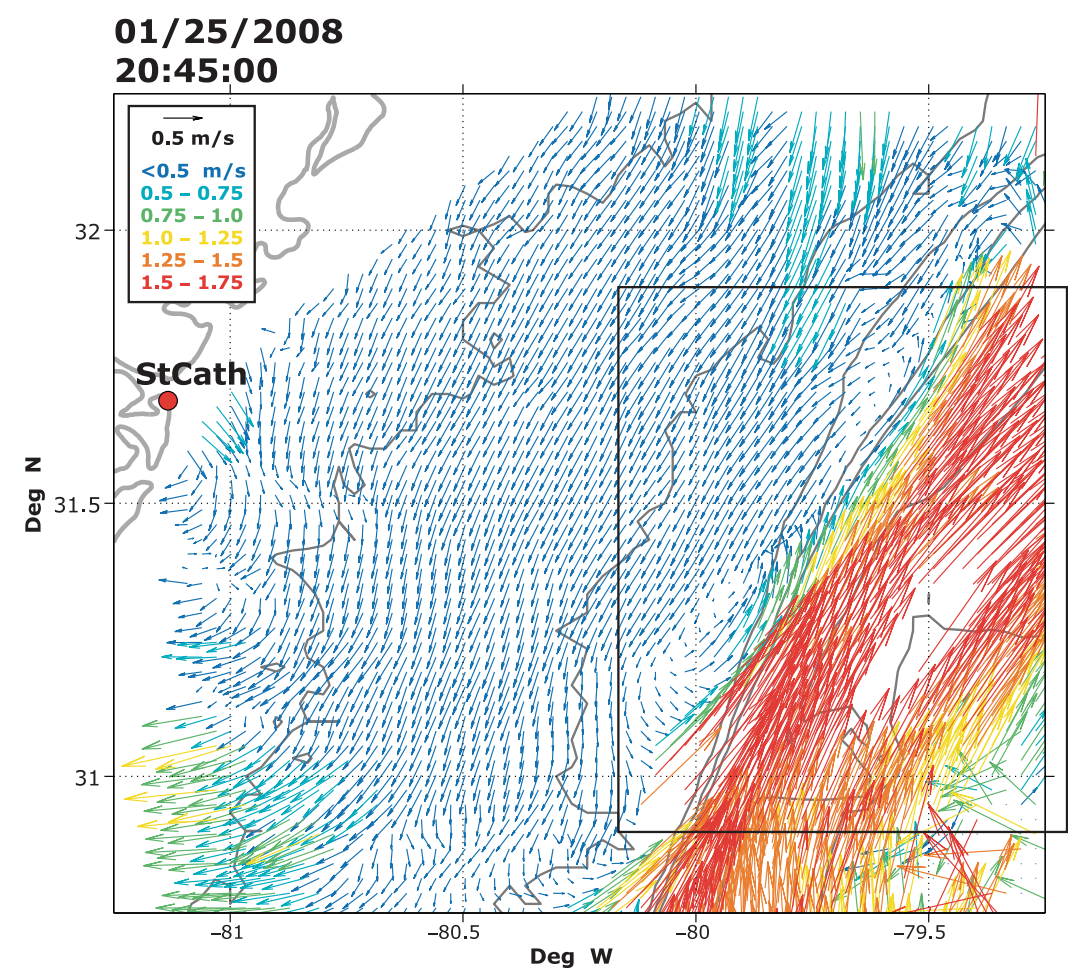

Figure 1. Surface velocities from Wellen Radar (WERA) long range HF-radars on Pritchard's Island SC and St. Catherine's Island GA. Radars transmit at $8.3 \mathrm{MHz}$ and yield $\sim 200 \mathrm{~km}$ range with $3 \mathrm{~km}$ range resolution and $2^{\circ}$ azimuthal resolution $\sim 3$ $\mathrm{km}$ resolution at $100 \mathrm{~km}$ range). Isobaths are 20, 40, 60, 80, 100, 250, $500 \mathrm{~m}$.

as high as 3-8 $\times 10^{-5} / \mathrm{sec}$, a significant fraction of local planetary vorticity $\left(\sim 7.5 \times 10^{-5} / \mathrm{sec}\right.$ at $31^{\circ} \mathrm{N}$ latitude).

\section{SETC Eddies}

[6] The probable importance of SETC eddies is threefold. First, they indicate an instability process operating at a previously unidentified frequency, scale, and cross-shelf position, contributing directly to the GS energy budget. Several decades of careful interdisciplinary work correlated GS meander decay to net nutrient import in specific locations, demonstrating an intimate link between GS low frequency energetics and property transport across the shelf edge [Lee et al., 1991]. SETC eddies could contribute similarly, or interact with other instability processes to alter GS meander energetics in specific locations. Secondly, SETC eddies could transfer momentum and define the process by which the GS directly affects subtidal variability on the outer shelf. While the correlation between subtidal variability on the outer shelf and Gulf Stream variability is well-known [Atkinson et al., 1983], the physical processes to support causation have not been defined. As a pulsed process affecting momentum transport between the GS and the outer shelf, they should be represented in horizontal eddy diffusivities along ocean basin boundaries - a topic of interest since Munk [1950], continuing to the present [Jochum et al., 2008]. Finally, SETC eddies may effectively transport properties across the shelf edge, including the net import of nutrients into the euphotic zone on the shelf, and transfers of heat between the GS and the adjacent coastal ocean. Newly defined denitrification processes (sinks) in the global coastal ocean imply much higher fixation and input rates (sources) than are presently identified [Codispoti, 2007], requiring a more accurate accounting of nitrate sources at the shelf edge. As a primary vector for global heat redistributions, processes altering heat and momentum content of the GS need to be understood to represent them adequately in global circulation models, upon which climate predictions are based.

\subsection{Instability Process}

[7] Mixed baroclinic and barotropic instabilities generate low frequency GS meanders [Dewar and Bane, 1985; Luther and Bane, 1985], and may also account for shelfbreak front eddies in the Middle Atlantic Bight [Lozier et al., 2002]. Instability may also contribute to SETC eddies, due to strong gradients in alongshelf velocity, density and depth across the shelf-edge. For barotropic instability, one necessary condition is that the horizontal gradient of potential vorticity $\Pi$ must change sign somewhere within the region [Bower, 1989; Pedlosky, 1987]. Estimates for П are derived from mean representations of each contributing factor, for both baroclinic $\Pi=\frac{(f+\zeta)}{\rho} \frac{\partial \rho}{\partial z}$ and barotropic $\Pi=\frac{(f+\zeta)}{h}$ expressions $(f$ is local vertical planetary vorticity, $\zeta$ is local vertical relative vorticity, estimated as the crossshelf shear in alongshelf velocity, $\rho$ is density and $h$ is water depth). Such estimates only roughly represent the undisturbed background $\Pi$, as the effects of active instability processes are included [Pedlosky, 1987]. $\zeta$ ranges from near zero on the mid shelf to greater than $6.0 \times 10^{-5} / \mathrm{sec}$ at the shelf edge when the $M_{2}$ tide is oriented southwestward, or $\sim 0.8 \mathrm{f}$, with maximum cross-shelf gradient situated just shoreward of the shelf break. $f$ changes by only $3 \%$ 


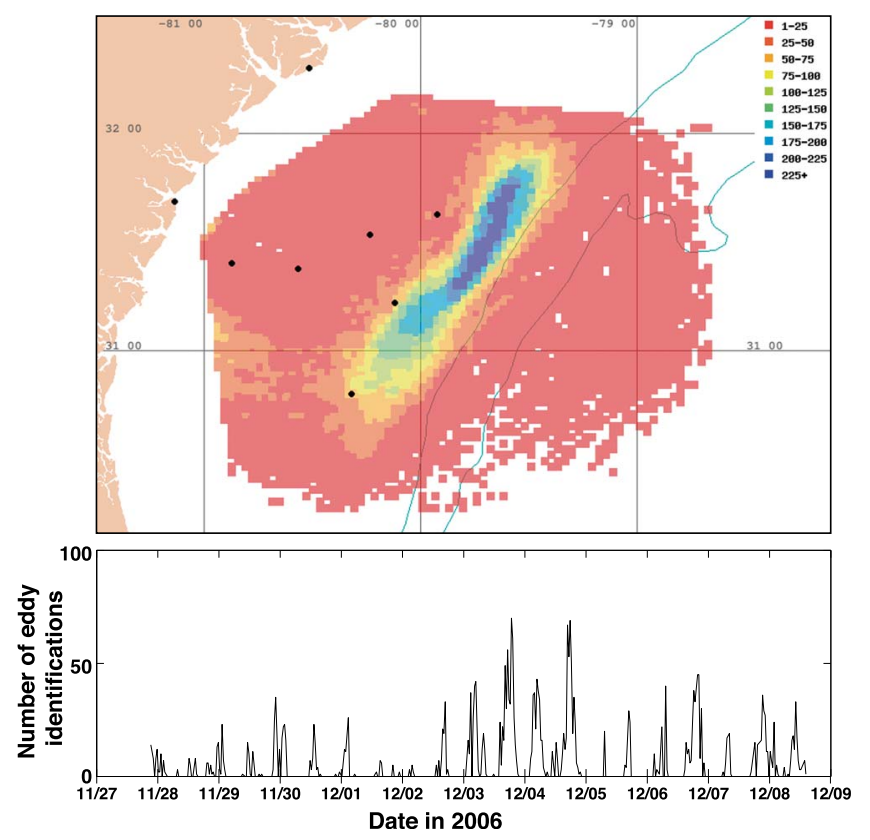

Figure 2. Artificial neural network results for the period April 2006-August 2007. (top) A map of numbers of positive returns for eddy features at gridpoints. (bottom) A partial timeseries of numbers of eddy incidence.

crossing normal from the shore past the slope, but $h$ changes from 40 to $400 \mathrm{~m}$ over the horizontal distance of $50 \mathrm{~km}$ at the shelf edge ( $1 / h$ range: $\left.0.025-0.0025 \mathrm{~m}^{-1}\right)$, providing a very strong topographic Beta effect. A mean density field does not exist in the literature for the very shallow margins of the GS adjacent and overlying the outer shelf and slope, but available CTD sections indicate low values of $\frac{1}{\rho} \frac{\partial \rho}{\partial z}: \sim 1-3$ orders of magnitude smaller than $1 / h$ ranges at the shelf edge, with small cross shelf gradients, such that the barotropic expression of $\Pi$ is most suitable. The topographic beta effect dominates just seaward of the shelf break, reversing the sign of the gradient in $\Pi$ dominated by $\zeta$ just shoreward of the shelf break, thus satisfying a necessary, though not sufficient condition for barotropic instability.

\subsection{Momentum Flux}

[8] In late June through July 2009, one shelf edge mooring was deployed in $46 \mathrm{~m}$ depth water to ascertain the subsurface expression of the SETC eddies. Instrumentation included one bottom mounted RDI $300 \mathrm{kHz}$ ADCP sampling cross-shelf $(u)$ and alongshelf $(v)$ velocities and a co-located lower water column temperature $(\mathrm{T})$ chain with twenty ONSET HOBO $\mathrm{T}$ sensors (all at $1 \mathrm{~m}$ depth resolution, 15 minute intervals). Mooring data were separated into high frequency and low frequency components (60 hour Hanning window filter) and used to estimate eddy covariances $\left\langle u^{\prime} v^{\prime}\right\rangle$ (primes indicate record long means removed, angle brackets denote temporal average). GS meander eddy variability should appear in the low pass data, while higher frequency processes including SETC eddies should appear in the high pass data. Eddy-correlation estimates from archived 40 hour low pass $u, v$ and $\mathrm{T}$ from continental slope moorings along the southeast United States were used to establish a correspondence of GS meander decay regions with regions of net nutrient import onto the continental shelf [Lee et al., 1991]. Those results provide eddy-correlation magnitudes from a low frequency process of proven importance against which magnitudes from the high pass new data can be compared.

[9] Resulting high pass and low pass $\left\langle u^{\prime} v^{\prime}\right\rangle$ magnitudes do support the importance of high pass processes along the outer shelf off Georgia. Estimates from the high pass ADCP velocities range from -0.0045 (0.001 standard error) below the thermocline to $+0.0012(0.003) \mathrm{m}^{2} / \mathrm{s}^{2}$ near surface for the high pass, compared to Lee et al.'s [1991] low pass estimates of $0.003-0.08 \mathrm{~m}^{2} / \mathrm{s}^{2}$ from slope moorings between $30.0^{\circ} \mathrm{N}$ and $32.5^{\circ} \mathrm{N}$. The sign of the large negative subthermocline high pass eddy covariance is consistent with shoreward transport of positive alongshelf velocity perturbations. This is in the opposite sense than the "negative eddy viscosity' low pass estimates by Webster [1961] for the apparent meander decay region off Onslow Bay, NC, later verified by Brooks and Bane [1981], and for the decay regions upstream from the Charleston Bump and off Onslow Bay identified by Lee et al. [1991]. With positive background cross shelf gradient in $v$, this implies that high frequency processes are extracting energy from the mean and transporting positive alongshelf momentum shoreward. Eddy covariances from a synthetic timeseries for the mooring location (with $\mathrm{M} 2, \mathrm{~S} 2, \mathrm{~N} 2, \mathrm{O} 1$ and $\mathrm{K} 1$ tidal constituents from the ADCIRC tidal model [Luettich and Westerink, 1992]) are near zero, indicating that the linear astronomical tide is not responsible for this transport.

\subsection{Cross-Shelf Property Exchange}

[10] Estimates of $\left\langle u^{\prime} T^{\prime}\right\rangle$ were made for the lower water column by averaging the subthermocline $\mathrm{T}$ sensors and the lower ADCP bins. Measured T values usually fell within the range governed by Atkinson et al.'s [1984] empirical inverse relationship between $\mathrm{T}$ and nitrate $\left(\mathrm{NO}_{3}^{-}\right)$concentration, so these estimates correlate with $\left\langle u^{\prime} \mathrm{NO}_{3}^{-\prime}\right\rangle$. Both high pass and low pass estimates are two orders of magnitude lower (and do not quite exceed their standard errors) than Lee et al.'s [1991] low pass estimates of -0.1 to $+0.2 \mathrm{~m} / \mathrm{s}^{\circ} \mathrm{C}$. However, the dynamic range of $\mathrm{T}$ is lower at this outer shelf location than for the slope moorings used for Lee et al.'s [1991] low pass estimates, consistent with the lower low pass estimates from the present dataset, and lower than it would be in the center of the high eddy incidence zone of Figure 2, so this temporal mean may not accurately represent the importance of the process. A timeseries of the cumulative sum $\left(\sum_{\mathrm{c}}\right)$ of high pass $u^{\prime} T^{\prime}$ is characterized by a sequence of distinct positive jumps, separated by periods of relatively constant values (Figure 3), as might result from a sequence of identifiable events.

[11] HF-radar surface velocity fields indicate those events are SETC eddies. From July 8-13 2009 (full moon July 6-8) eddies are especially prevalent, with southwest migrating SETC eddy sequences during each southwestward oriented phase of the shelf edge tide from the morning of July 8th through the morning of the 13th (two sequences are shown in Figure 3-others from the six day period are similar). Note that $\sum_{\mathrm{c}} u^{\prime} T^{\prime}$ approximately doubles over these 6 days. Snapshots of HF-radar surface velocity fields from other times coincident with jumps in this record also show SETC eddies located near the mooring. Eddy centers can migrate 

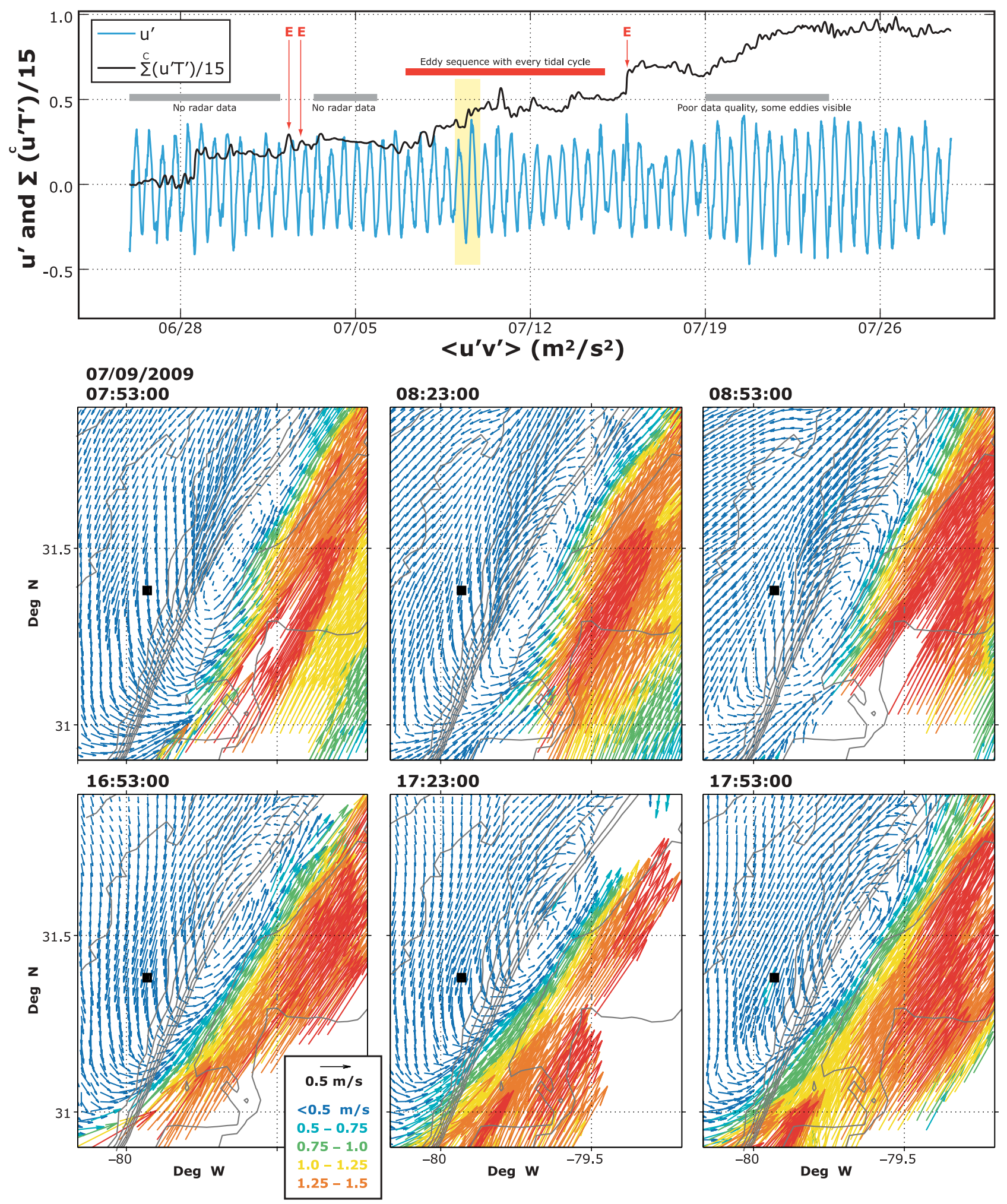

Figure 3. SETC eddy effect on high pass eddy covariance estimates. Top panels) Timeseries of $\sum_{\mathrm{c}} u^{\prime} T^{\prime}$ estimates (black line - values divided by 15) from mooring subthermocline high pass ADCP cross-shelf velocity (blue line) and T sensors. Red 'E's indicate HF-radar images with SETC eddy near mooring, coincident with a sudden jump $\sum_{\mathrm{c}} u^{\prime} T^{\prime}$. The yellow bar indicates July 9th data, from which the panels in $\mathrm{b}$ are selected. Middle and bottom panels) HF-radar surface currents showing two sequences of SETC eddies propagating equatorward during the two southwestward oriented phases of the shelf tide on July 9, 2009. 
$20 \mathrm{~km}$ or more in half an hour, or over $10 \mathrm{~m} / \mathrm{s}$. This implies the eddies are not coherent translating water columns, but are local temporary responses to a propagating disturbance. Their net effect at the mooring location is a non-negligible contribution to shelf edge shoreward heat, nitrate, and momentum fluxes.

\section{Relevance}

[12] Along with the abrupt positive $\sum_{\mathrm{c}} u^{\prime} T^{\prime}$ jumps, the more gradual rise over July $8-13$ suggests eddy signatures can accrue in mooring data over more extended timeframes. Eddy covariances were thus estimated for available mooring hourly datasets in the southeast to see if similar high frequency processes may be detected elsewhere, where HF-radar has not yet been installed. Frontal Eddy Dynamics Experiment (1987 [Ebbesmeyer et al., 1989]) and several Minerals Management Service-sponsored (1992-1994 [Berger et al., 1995]) moorings were located on the North Carolina outer shelf south of Cape Hatteras, where the GS is also situated very nearshore, but where tidal magnitudes on the shelf are significantly smaller than on the shelf off Georgia. Low pass estimates from $400 \mathrm{~m}$ isobath moorings are consistent in sign and magnitude with those from similar depths of Lee et al. [1991] for Onslow Bay, while high pass estimates from 60 to $75 \mathrm{~m}$ isobath moorings are of the same order as those discussed here for the 2009 Georgia dataset from $46 \mathrm{~m}$ depth. SETC eddies thus appear to be present all along the southeast United States, even where tides diminish from their maximum magnitude off Georgia. With similarly energetic tides on the continental shelves of Brazil, Australia, the Philippines, Taiwan, China and Japan, all with adjacent western boundary currents, conditions conducive to SETC eddies exist world-wide, so that the process may have global significance.

[13] Defining cross-shelf exchange mechanisms continues to be one of the more important challenges in ocean science, as cross-shelf pathways and shelf residence times are of significance to a wide range of interdisciplinary topics in the coastal ocean. GS meander eddies and associated nutrientrich cold-water intrusions are sporadic events: SETC eddies are far more ubiquitous, appearing twice daily through much of each lunar cycle. Defining the effect of SETC eddies on nutrient and property transports up and over the southeast United States shelf and other shelves where they might exist is therefore of broad interest.

[14] The relationship of SETC eddies to a western boundary current indicates still higher relevance, due to their potential influence on heat, momentum, and energy distributions within this important global heat distribution system. Observationally-based GS meander energetics studies to date have revealed a rich interplay between barotropic and baroclinic processes, but have been conducted with lowpassed data [Brooks and Bane, 1981; Dewar and Bane, 1985; Lee et al., 1991; Dewar and Bane, 1989], which excludes tide-correlated processes. SETC eddies on the Georgia shelf extract energy from the mean, opposite to the effect of the GS meander eddies there. Potential interactions between processes operating in different frequency regimes is inherently non-linear, and difficult to assess from an observational perspective alone. But representing the SETC eddies with fidelity in models as a process or a pulsed horizontal eddy viscosity will require observationally based detailed under- standing of the process under a range of forcing. These early results provide the basis for more intensive investigation of these energetic features.

[15] Acknowledgments. Ship days on the R/V Savannah were provided by Skidaway Institute of Oceanography. HF-radar funding was provided by the Georgia Research Alliance, ONR grant N00014-02-10972, NOAA grants NA07NOS47302195, NA08NOS4730409 and NSF grant OCE-0536326. Anna Boyette constructed the figures.

\section{References}

Atkinson, L. P., T. N. Lee, J. O. Blanton, and W. S. Chandler (1983), Climatology of southeastern United States shelf waters, J. Geophys. Res., 88, 4705-4718.

Atkinson, L. P., P. O’Malley, J. Yoder, and G. Paffenhofer (1984), The effect of summertime shelf break upwelling on nutrient flux in southeastern United States continental shelf waters, J. Mar. Res., 42, 969-993.

Berger, T. J., P. Hamilton, R. J. Wayland, J. O. Blanton, W. C. Boicourt, J. H. Churchill, and D. R. Watts (1995), A physical oceanographic field program offshore North Carolina, Tech. Rep. OCS Study MMS 94-0047, U.S. Dep. of the Inter., Miner. Manage. Serv., New Orleans, La.

Blanton, B. O., F. E. Werner, H. E. Seim, R. A. Luettich Jr., D. R. Lynch, K. W. Smith, G. Voulgaris, F. M. Bingham, and F. Way (2004), Barotropic tides in the South Atlantic Bight, J. Geophys. Res., 109, C12024, doi:10.1029/2004JC002455.

Bower, A. S. (1989), Potential vorticity balances and horizontal divergence along particle trajectories in Gulf Stream meanders east of Cape Hatteras, J. Phys. Oceanogr., 19, 1669-1681.

Brooks, D. A., and J. M. Bane (1981), Gulf Stream fluctuations and meanders over the Onslow Bay upper continental shelf, J. Phys. Oceanogr., $11,247-256$.

Castellani, M. (2006), Identification of eddies from sea surface temperature maps with neural networks, Int. J. Remote Sens., 27, 1601-1618.

Codispoti, L. A. (2007), An oceanic fixed nitrogen sink exceeding $400 \mathrm{tg}$ $\mathrm{N} \mathrm{a}^{-1}$ vs the concept of homeostasis in the fixed-nitrogen inventory, Biogeosciences, 4, 233-253.

Dewar, W. K., and J. M. Bane (1985), Subsurface energetics of the Gulf Stream near the Charleston Bump, J. Phys. Oceanogr., 15, 1771-1789.

Dewar, W. K., and J. M. Bane (1989), Gulf stream dynamics. Part II: Eddy energetics at $73^{\circ} \mathrm{W}, J$. Phys. Oceanogr., 19, 1574-1587.

Ebbesmeyer, C. C., et al. (1989), Frontal Eddy Dynamics FRED Experiment off North Carolina, Tech. Rep. OCS Study MMS 86-0082, U.S. Dep. of the Inter., Miner. Manage. Serv., Hearndon, Va.

Fratantoni, P. S., and R. S. Pickart (2003), Variability of the shelf break jet in the Middle Atlantic Bight: Internally or externally forced?, J. Geophys. Res., 108(C5), 3166, doi:10.1029/2002JC001326.

Garvine, R. W., K.-C. Wong, and G. G. Gawarkiewicz (1989), Quantitative properties of shelfbreak eddies, J. Geophys. Res., 94, 14,475-14,483.

Jochum, M., G. Danabasoglu, M. Holland, Y.-O. Kwon, and W. G. Large (2008), Ocean viscosity and climate, J. Geophys. Res., 113, C06017, doi:10.1029/2007JC004515.

Lee, T. N., J. A. Yoder, and L. P. Atkinson (1991), Gulf Stream Frontal Eddy Influence on Productivity of the Southeast U.S. Continental Shelf, J. Geophys. Res., 96, 22,191-22,205.

Lozier, M., M. Reed, and G. Gawarkiewicz (2002), Instability of a shelfbreak front, J. Phys. Oceanogr., 32, 924-944.

Luettich, R., and J. Westerink (1992), A three dimensional circulation model using a direct stress solution over the vertical, in Computational Methods in Water Resources IX, edited by T. Russell et al., Comput. Mech., Southhampton, U. K.

Luther, M., and J. M. Bane (1985), Mixed instabilities in the Gulf Stream over the continental slope, J. Phys. Oceanogr., 15, 3-23.

Munk, W. (1950), On the wind-driven ocean circulation, J. Meteorol., 7 79-93.

Munk, W., L. Armi, K. Fischer, and F. Zachariasen (2000), Spirals on the sea, Proc. R. Soc. A, 456, 1217-1280.

Pedlosky, J. (1987), Geophysical Fluid Dynamics, 2nd ed., Springer, New York.

Pietrafesa, L. J., G. S. Janowitz, and P. A. Wittman (1985), Physical oceanographic processes in the Carolina Capes, in Oceanography of the Southeastern U.S. Continental Shelf, Coastal Estuarine Sci., vol. 2, edited by L. P. Atkinson, D. W. Menzel, and K. A. Bush, pp. 23-32, AGU, Washington, D. C.

Shay, T. J., J. M. Bane, D. R. Watts, and K. L. Tracey (1995), Gulf Stream flow field and events near $68^{\circ} \mathrm{W}$, J. Geophys. Res., 100, $22,565-22,589$ 
Webster, F. A. (1961), A description of Gulf Stream meanders off Onslow Bay, Deep Sea Res., 8, 130-143.

J. A. Amft, E. Edwards, T. Moore, D. K. Savidge, and C. Smith, Skidaway Institute of Oceanography, 10 Ocean Science Cir., Savannah, GA 31411, USA. (dana.savidge@skio.usg.edu)
J. Norman, College of Science and Technology, Armstrong Atlantic State University, 11935 Abercorn St., Savannah, GA 31419, USA.

G. Voulgaris, Marine Science Program, Department of Geological Sciences, University of South Carolina, EWS 617, Columbia, SC 29208, USA. 